\title{
A RELAÇÃ̃o ENTRE A DESIGUALDADE E A CORRUPÇÃo POLÍTICA NA FILOSOFIA DE ROUSSEAU
}

\author{
Vital Francisco Celestino Alves ${ }^{1}$ \\ Universidade de Brasilia (UnB) \\ https://orcid.org/0000-0001-9072-5002
}

\section{RESUMO:}

O problema da desigualdade se apresenta como um constante objeto de reflexão na filosofia de Rousseau, perpassando diversas de suas obras. Buscando analisar a relação entre a desigualdade social e a corrupção política no pensamento rousseauniano mediante a defesa da hipótese de que a desigualdade social se configura em um fenômeno responsável pelo advento da corrupção política, pretende-se, nesse artigo, primeiro: examinar as distinções entre a desigualdade natural e a desigualdade social, ou seja, demarcar suas especificidades e como Rousseau compreende cada uma delas; segundo, avaliar como a desigualdade social pode produzir a corrupção política, isto é, entender porque a desigualdade de riquezas ao produzir o luxo pode consequentemente engendrar a corrupção política, e, terceiro, ambiciona-se demonstrar quais são as consequências mais drásticas da desigualdade social na república. Com isso, almeja-se instaurar um frutífero debate e uma consistente reflexão.

PALAVRAS-CHAVE: Desigualdade; Luxo; Corrupção política; Rousseau.

\section{THE RELATIONSHIP BETWEEN SOCIAL INEQUALITY AND POLITICAL CORRUPTION IN THE PHILOSOPHY OF ROUSSEAU}

\begin{abstract}
:
The problem of inequality is presented as a constant object of reflection in the philosophy of Rousseau, pervading several of his works. Seeking to analyze the relationship between social inequality and political corruption in Rousseau's thought, through the defense of the hypothesis that social inequality is a phenomenon responsible for the advent of political corruption, we intend, in this article, first, to examine the distinctions between natural inequality and social inequality, or establish their specific characteristics, as Rousseau understands each; second, to analyse how social inequality can produce political corruption, that is, to understand why inequality of wealth, in producing luxury, can thus engender political corruption, and thirdly, to show which are the most drastic consequences of social inequality in the republic. Thus, we aim to establish a fruitful debate and a consistent reflection.
\end{abstract}

KEYWORDS: Inequality; Luxury; Political corruption; Rousseau.

\footnotetext{
${ }^{1}$ Doutor em Filosofia pela Universidade Federal de Goiás (UFG), Goiás - Brasil. Professor Assistente vinculado ao Departamento de Filosofia da Universidade de Brasília (UnB), Brasília - Brasil. E-mail: vitalalves1@gmail.com
}

ALVES, Vital Francisco Celestino. A relação entre a desigualdade e a corrupção política na filosofia de Rousseau. Griot : Revista de Filosofia, Amargosa/Bahia, v.17, n.1, p.85-96, junho/2018. 


\section{Da desigualdade natural à desigualdade social}

O tema da desigualdade perpassa várias obras de Rousseau ${ }^{2}$. Para compreender a sua acepção "social" e demonstrar que ela se configura em um dos fenômenos responsáveis por alavancar o surgimento da corrupção política ${ }^{3}$ deve-se inicialmente, aludir ao Discurso sobre a origem e os fundamentos da desigualdade entre os homens ${ }^{4}$ para atestar, posteriormente, a presença do problema em outros escritos rousseauístas. No proêmio dessa obra, o filósofo genebrino imputa à espécie humana dois tipos de desigualdade: a primeira, natural ou física, estipulada pela natureza e caracterizada pelas diferenças de idade, saúde, forças corpóreas e espirituais; a segunda, denominada de desigualdade moral ou política ${ }^{5}$, a qual resulta de uma convenção ${ }^{6}$ ou aprovação dos homens na sociedade e se refere aos vários privilégios desfrutados por alguns em prejuízo de outros, como serem mais ricos e poderosos e, ainda, por imporem obediência aos materialmente destituídos.

Evidentemente, não é possível indagar sobre a gênese das diferenças naturais, defende Rousseau, à medida que o próprio termo "natural" enuncia sua definição e significado. Tampouco se pode buscar qualquer nexo entre as distinções naturais e a desigualdade social, essa tentativa equivaleria a questionar se os homens que mandam são mais honrados do que aqueles que obedecem e se a robustez corpórea ou espiritual, assim como a sabedoria e a virtude usualmente se situam, nos mesmos indivíduos, no que diz respeito à dimensão do poder e da riqueza. Pode-se considerar, desse modo, que na percepção rousseauniana a primeira desigualdade não pode ser cotejada com a segunda e, mais do que isso, enquanto a natural é aceitável, a social é perniciosa.

Ao reverso, no tocante à desigualdade social, Rousseau expõe - depois de analisar preliminarmente as peculiaridades do homem em estado de natureza e o contexto no qual supostamente ele vivia - na segunda parte do Segundo discurso o

\footnotetext{
${ }^{2}$ Mostraremos no desenrolar deste tópico como o referido tema encontra-se presente em inúmeras obras rousseaunianas.

3 Para Alberto Burgio (1989), o germe da corrupção deriva de uma sociedade dominada pela desigualdade. Existe em Rousseau uma teoria do progresso circular da desigualdade social e suas implicações no meio político e institucional, que lembra a passagem dos Discursos, de Maquiavel, consagrada a analisar as sucessivas formas de governo: do principado seguido da república, e aquelas nas quais se instaura em uma dialética entre corrupção e reação o domínio da corrupção.

${ }^{4}$ Doravante vamos nos referir a esse texto simplesmente como Segundo Discurso.

${ }^{5}$ Essa segunda desigualdade é abordada por Rousseau, sobretudo, na Economia política, na segunda parte do Segundo Discurso e no Contrato social; especialmente no que concerne às diferenças sociais entre ricos e pobres. Analisar tal forma de desigualdade e as razões pelas quais ela produz a corrupção é o principal objetivo desse artigo e tópico e a designaremos de "desigualdade social".

${ }^{6}$ Buscando analisar a origem da desigualdade entre os homens, Rousseau explicita o processo que consolidou uma sociedade em que reina a desigualdade social partindo da hipótese do estado de natureza e demonstrando que a sociedade civil foi fundada por um pacto entre ricos e pobres. Em síntese, um acordo que deu origem a uma sociedade alicerçada em leis que favoreceram os mais abastados, fixou a lei da propriedade e da desigualdade social e submeteu o gênero humano ao trabalho, à servidão e à miséria. Se, no Segundo discurso, o filósofo genebrino percorre o itinerário que culminou na solidificação de uma sociedade marcada pela desigualdade, no Contrato social, Rousseau expõe um pacto de associação que se contrapõe idealmente ao chamado "pacto dos ricos", denunciado no Segundo Discurso, pois o modelo de pacto apresentado no Contrato se propõe asseverar a igualdade e a liberdade tornando os indivíduos cidadãos de uma república.
}

ALVES, Vital Francisco Celestino. A relação entre a desigualdade e a corrupção política na filosofia de Rousseau. Griot : 
declínio do homem, isto é, narra a partir de uma conjectura histórica como o homem abandona a sua integridade e o modo de vida simples e faz-se perverso e tacanho com seus semelhantes. Em suma, a narrativa adotada pelo autor se inicia expressando que algumas situações, bem como o crescimento populacional e as vicissitudes no meio ambiente (inundações, secas, incêndios e terremotos, por exemplo), levaram as pessoas a se aproximarem e buscarem novas formas de se preservarem. A aproximação, devido a tais fatores, contribuiu diretamente para o alvorecer do amor (efeito do convívio social e não sua causa) e o amadurecimento da sexualidade. $O$ convívio social proporcionou o nascimento dos afetos mais doces como o amor conjugal e o amor paterno e, ao mesmo tempo, um arroubo instintivo direcionado unicamente para uma efêmera cópula (como era no estado de natureza) se transformou em relações com exigência de uma exclusividade sublinhada pelo sentimento de ciúme, imprimindo assim a ideia da troca de favores e de competição entre os envolvidos. Somado à questão da sexualidade, os divertimentos partilhados, que os momentos de ócio propiciavam, sobretudo o canto e a dança, foram circunstâncias determinantes para uma transformação do homem. Nas palavras de Rousseau:

\begin{abstract}
Cada um começou a olhar os outros e a desejar ser ele próprio olhado, passando assim a estima pública a ter um preço. Aquele que cantava ou dançava melhor, o mais belo, o mais forte, o mais astuto ou o mais eloquente, passou a ser o mais considerado, e foi esse o primeiro passo tanto para a desigualdade quanto para o vício; dessas primeiras preferências nasceram, de um lado, a vaidade e o desprezo, e, de outro, a vergonha e a inveja. (ROUSSEAU, 1964, p. 169/170). ${ }^{7}$
\end{abstract}

O despontar desses novos germes sucedeu uma subversão da vida alvissareira e pueril dos primeiros tempos. A partir desse momento, as relações entre os homens passam a se caracterizar pelo amor próprio ao invés do amor de $\mathrm{si}^{8}$, posto que o desejo de ser admirado passa a prevalecer e as desconsiderações se converteram em ultrajes. Destarte, na medida em que um homem penalizava o desprezo que lhe era conferido, tendo como base equivalente o prestígio que imputava a si, as vinganças adquiriram proporções assustadoras e os homens tornaram-se cruéis e impiedosos. $\mathrm{O}$ autor genebrino acrescenta que algumas vicissitudes materiais também contribuíram

\footnotetext{
${ }^{7}$ Chacun commença à regarder les autres et à vouloir être regardé soi-même, et l'estime publique eut um prix. Celui qui chantoit ou dansoit le mieux; le plus beau, le plus fort, le plus adroit ou le plus eloquente devint le plus considere, et ce fut là le premier pas vers l'inégalité, et vers le vice em même terms: de ces premières préférences nâquirent d'um côté la vanité et le mépris, de l'autre la honte et l'envie. SD, II. OCR3. (Tradução nossa).

${ }^{8}$ Segundo Rousseau, o estabelecimento das relações entre os homens instaura no ser humano um desejo de se mostrar superior ao outro, tornando as relações humanas marcadas pelo desejo de dominação e pela necessidade de ser admirado. Esse desejo recorrente entre os homens desdobra-se em inúmeras rivalidades e conflitos. $O$ amor próprio - que pode ser entendido como vaidade ou orgulho, em outras palavras, como a autoavaliação que faz o homem se comparar com o outro e julgar-se melhor e superior - passa a prevalecer sobre o amor de si, aquela paixão primitiva e inata ao homem que é predecessora de todas as outras e igualmente sua origem e princípio. Logo, a partir do momento ao qual nos referimos, o amor de si, caracterizado pelo bem inato e plácido, é abandonado e, em seu lugar, o amor próprio - marcado pelo bem fraudulento e embasado no desejo de dominar o outro adquire força e passa a prevalecer.
}

ALVES, Vital Francisco Celestino. A relação entre a desigualdade e a corrupção política na filosofia de Rousseau. Griot : 
para o alvorecer de um novo juízo, que os homens passaram a emitir sobre si mesmos e sobre os demais.

Segundo Rousseau, o advento da metalurgia e da agricultura alargaram os poderes e as necessidades do homem. Fazendo com que a propriedade e o direito de posse tomassem uma relevância até então desconhecida. A concepção de direito de posse transfigurou-se na ideia de demonstração de poder, hegemonia e forma; ideia pela qual os homens começaram a se diferenciar e a sobrepor sobre os demais essa diferença. $O$ genebrino argumenta que essas transfigurações fomentaram no homem a ambição e um fervoroso desejo de edificar sua riqueza, não imperiosamente para suprir suas carências materiais, mas para que pudessem se inscrever em uma posição superior quando contrastada à dos outros. $O$ resultado foi infausto na medida em que guiou os homens a agirem com frequência de maneira vil, almejando prejudicarem-se reciprocamente em decorrência de uma íntima inveja. Progressivamente, confeccionou-se um cenário de enfrentamentos, explorações e rivalidades que tornaram o convívio social insustentável.

É nesse contexto - por intermédio do pacto entre ricos e pobres - que se origina a sociedade política cimentada na extirpação da liberdade natural e amparada em leis que protegem a propriedade dos ricos e mantém a ampla desigualdade entre as classes sociais. $O$ governo institucionalizado nessa base condensa o poder, a riqueza e a dominação dos ricos sobre os pobres. Portanto, os regimes políticos surgidos a partir desse horizonte têm como característica a desigualdade. Essa marca da desigualdade social - antagonismo entre ricos e pobres foi alvo de alguns comentários pertinentes. Vejamos alguns deles. Na interpretação de Alberto Burgio (1989), a relação entre ricos e pobres tonifica a estrutura fundamental da desigualdade social na ordem política e tem como característica a subserviência. Grosso modo, a desigualdade estabelece condições para o alvorecer da dependência pessoal ${ }^{9}$. Judith Shklar (1978), por sua vez, alega que a concepção rousseauniana, ao retratar a extrema desigualdade social, busca denunciar paralelamente a necessidade de se eliminar a concentração de riqueza como prérequisito para assegurar a liberdade. Considerando a perscrutação realizada brevemente, e a ênfase desses dois comentários sobre o processo da desigualdade, julgamos que agora há condições para se confirmar como a desigualdade social pode ser danosa a um regime republicano.

\section{Desigualdade social e luxo}

$\mathrm{O}$ entendimento sobre a passagem da desigualdade natural à desigualdade social nos conduz à indagação: por que a desigualdade social é nociva à república? Sabe-se, de antemão, que ela engendra a corrupção e esse é um dos fatores preponderantes para considerá-la deletéria. Mas, como ela gera a corrupção? Genericamente, considera-se que a ordem política constituída pelo pacto dos ricos torna a desigualdade social uma realidade, viabilizando um cenário de enorme antagonismo entre ricos e pobres. $O$ que inevitavelmente cria condições para que a corrupção emerja.

\footnotetext{
${ }^{9}$ Retomaremos a essa questão no final desse artigo. 
Em seu verbete Economia (moral e política) 10 - redigido no mesmo ano do Segundo Discurso (1755) -, Rousseau já delineia com clareza os malefícios da desigualdade social e sua relação direta com a corrupção política. Ao tratar das incumbências do governo em uma república - no verbete -, o cidadão de Genebra declara que uma das funções primordiais do governo é refrear a extrema desigualdade de riquezas. Para desempenhar essa função, o governo não precisa desempossar a fortuna daqueles que a detém, mas, sim, criar dispositivos capazes de impedir a concentração de riqueza e impossibilitar que os cidadãos se depauperem. Quando um governo não consegue exercer essa função, prevalece um ordenamento desigual pelo território do país e, consequentemente, reina uma mentalidade que se opõe ao espírito republicano, ou seja, surge um

estímulo das artes voltadas para o luxo (destinadas para o prazer) e das artes puramente industriais, à custa das atividades úteis e laboriosas, o sacrifício da agricultura em favor do comércio, a necessidade de delegar a cobrança dos impostos, devido à má administração dos recursos do Estado; em suma, a venalidade levada a tal extremo que se atribua um valor em dinheiro até mesmo à estima pública, e a virtude tenha um preço no mercado - estas são as causas mais óbvias da opulência e da pobreza, da substituição do interesse público pelo particular, do ódio recíproco dos cidadãos, da indiferença à causa comum, da corrupção do povo (...) (ROUSSEAU, 1964, p. 258). ${ }^{11}$

Avaliamos que esse fragmento expressa os motivos pelos quais a desigualdade social é malfazeja à ordenação republicana, visto que ela se configura em um fenômeno marcado pela aglutinação de riqueza e produz uma visão política divergente ao modelo proposto por Rousseau. A desigualdade social tem sérios desdobramentos, como se pôde comprovar pelo trecho elencado, entre eles evidenciam-se o luxo ${ }^{12}$ e, finalmente, o problema mais grave para a república, a

\footnotetext{
10 Segundo Gérard Namer (1999), o verbete constitui um esforço rigoroso de Rousseau em explicitar um quadro de causas da desigualdade na sociedade. $O$ texto rousseauniano nos possibilita contrastar a sociedade marcada pela desigualdade com a sociedade fundamentada na igualdade e serve como ponto de partida para a oposição entre tipos de sociedade, o que se constata em textos posteriores de Rousseau. Pelos comentários desse intérprete, percebe-se que no Contrato social há a existência de sociedades naturais, como a família, a sociedade do gênero humano que precede o pacto social. $\mathrm{O}$ intérprete resume a sua opinião da seguinte maneira: as sociedades desiguais se apresentam de duas formas. A primeira: a sociedade da desigualdade antes do contrato, que quiçá finda na "sociedade geral" e, a segunda: a sociedade que se inclina a corromper a sociedade legítima. Em relação às sociedades embasadas na igualdade e legítimas, aponta-se que são aquelas nas quais impera a vontade geral e nas quais prevalecem um governo intermediário entre os cidadãos e os súditos.

11 Les arts d'agrément et de purê industrie favorisés aux dépens des métiers utiles et pénibles; l'agriculture sacrifiée au commerce; le publicain rendu nécessaire para la mauvaise administration des deniers de l'état; enfim la vénalité poussée à tel excès, que la considération se compte avec les pistoles, et que les vertus mêmes se vendent à prix d'argent: telles sont les causes les plus sensibles de l'opulence et de la misere, de l'intéret particulier substitué à l'intéret public, de la haine mutuelle des citoyens, de leur indifférence pour la cause commune, de la corruption du peuple (...). EP, II. OCR3. (Tradução nossa).

12 Tema recorrente no século XVIII e escopo de severas críticas de Rousseau. Uma vez que, se contrapõe diretamente à ideia de frugalidade e costumes simples que o modelo republicano preconizado pelo pensamento rousseauísta.
}

ALVES, Vital Francisco Celestino. A relação entre a desigualdade e a corrupção política na filosofia de Rousseau. Griot : 
corrupção política ${ }^{13}$. A saber, a desigualdade gera o luxo e produz a corrupção. A desigualdade, nesse sentido, não é perigosa simplesmente porque explicita uma profunda fratura entre ricos e pobres, mas também porque desencadeia efeitos que comprometem a visão política republicana.

O luxo se configura em uma reverberação da desigualdade social, mas para entender o seu significado, e respectivamente seu vínculo intrínseco com o problema da corrupção política na ordem política, faz-se necessário, previamente, evocar $O$ discurso sobre as ciências e as artes ${ }^{14}$ pois é nessa obra que se certificam as primeiras reflexões concernentes ao tema e na qual Rousseau começa mostrar-se um forte oponente ao luxo. Em síntese, no Primeiro discurso, buscando explanar a seguinte questão: "o restabelecimento das ciências e das artes terá contribuído para aprimorar os costumes?"15, Rousseau se esforça em defender, na primeira parte do Primeiro discurso, a tese de que as artes e as ciências costumam prosperar em sociedades que estão inseridas em contextos visivelmente decadentes e que se encontram moralmente debilitadas. Ao contrário, em uma sociedade reconhecida pela robustez moral e honra não costuma haver muita erudição. ${ }^{16}$

Na interpretação de N.J. H. Dent (1996), Rousseau identifica a lealdade à pátria e a coragem em defendê-la como o cerne do vigor moral. Relacionar, contudo, a força moral com a apatia pela erudição e, delimitar o seu contraponto à ruína moral com a apreciação pela erudição não revela senão um elo fortuito entre tais eventos. Para tanto, recorre ao modelo político romano rústico, dotado de coragem suficiente para não se curvar diante das atribulações; e ao regime espartano, composto por um povo de virtude, com intuito demonstrar com exemplos de povos virtuosos que não se corromperam aos vícios morais presentes nas ciências e nas artes. Todavia, somente na segunda parte do Primeiro discurso, o cidadão de Genebra desobstrui a cortina de fumaça que reveste a natureza do aludido elo e nomeia a ociosidade como explicação viável para se compreender a maneira como o declínio

${ }^{13}$ No tópico seguinte demonstraremos porque a corrupção pode ser considerada um problema grave para a república.

14 Na visão de Helena Rosenblatt (1997) e Michel Launay (1971), essa obra guarda uma imagem latente das intenções republicanas de Rousseau na medida em que nela, sem dúvida, o autor genebrino revela sua paixão pela justiça e pela igualdade. Além disso, entendemos que já esboça uma abordagem tocante à corrupção e pontua sua objeção a esse problema.

15 Em nota de rodapé referente ao Primeiro Discurso na edição brasileira (coleção Os Pensadores), Lourival Gomes Machado afirma que o tema proposto pela Academia Dijon é claramente setecentista, visto que na Europa, no século XVIII, as ideias iluministas preponderavam na vida intelectual e política e atingiam o apogeu da cultura inaugurada no Renascimento por intermédio do humanismo. Trata-se do período dos "filósofos" e dos "déspotas esclarecidos", ou seja, com eles prevalece a concepção de que a razão é o instrumento eficaz para restabelecer na sociedade a ordem natural observada no cosmos. Olhando por esse ângulo, os acadêmicos de Dijon apresentaram um tema que, indubitavelmente, desejavam ser respondido de maneira positiva. Mas Rousseau vai conferir a essa concepção uma resposta negativa e assim começa a trilhar o caminho do seu próprio pensamento em oposição às ideias que reinavam no período iluminista.

16 Para fortificar o seu argumento, o pensador genebrino remete a uma de suas referências republicanas incontestes: Catão, o Velho. Na perspectiva rousseauísta, Catão confrontou os pretenciosos e sutis que pervertiam a virtude e aniquilaram a coragem dos seus concidadãos. 0 domínio das ciências, das artes e da dialética abarrotou Roma de filósofos e oradores; negligenciou-se com isso a disciplina militar, vilipendiou-se a agricultura, os homens constituíram seitas e abandonaram a pátria.

ALVES, Vital Francisco Celestino. A relação entre a desigualdade e a corrupção política na filosofia de Rousseau. Griot : 
moral encontra-se associado à apreciação erudita.

A inferência de Rousseau é a de que o ócio dissipa gradativamente os $\operatorname{costumes}^{17}$ republicanos e extenua a virtude. Afasta as pessoas da obrigação de trabalhar para o próprio sustento, aguçando o encanto pela especulação e pelo saber requintado. Deve-se aqui lembrar de que a ociosidade combatida pelo autor se configura naquela voltada para as diversões triviais, as quais não são apenas inúteis, mas desfavoráveis porque extraí dos indivíduos a possibilidade de realizar algo em prol do seu semelhante. Além do mais, fabrica nos indivíduos uma renitente necessidade de exibicionismo, isto é, de exteriorizar feitos e excelências que ambicionam provocar o deslumbramento alheio, fazendo com que as análises e pesquisas, consequentemente, e de maneira geral, sejam realizadas não em vista do amor à verdade ou visando trazer vantagens para a humanidade, não obstante, carregando em seu núcleo exclusivamente o desejo de obter glória e elogios.

Ao mesmo tempo, ressalta Dent, Rousseau não pretende condenar as obras geniais de figuras como Descartes e Bacon, por exemplo. Em seu entendimento, esses homens não eram movidos pelas necessidades incitadas pelas instituições eruditas e nem mesmo pelo desejo de glória, ao contrário, suas pesquisas tinham como objetivo a busca da verdade. Fica claro, desse modo, que a crítica rousseauísta se direciona para um determinado tipo de erudito, ou seja, àquele que produz artes ou ciências inúteis e por intermédio delas busca tão somente exibir-se e tornar-se célebre. Sob a pena rousseauniana, artes e ciências inúteis - ainda seguindo a linha interpretativa de Dent -, oriundas da ociosidade causam efeitos daninhos de antemão porque representam uma perda de tempo para a sociedade, e isto em uma perspectiva política é um enorme malefício: o de deixar de fazer o bem, pois quando o cidadão se torna inútil ele se torna lesivo para a ordem política. $O$ desperdício de tempo com atividades frívolas consiste em um dano incomensurável, contudo pior do que esse desperdício, as ciências e as artes encontram-se amiúde acompanhadas de um perigo proveniente da ociosidade e nutridas pela vaidade; perigo esse ainda mais iníquo e rigorosamente diverso à vida republicana: o luxo. Na concepção rousseauniana, o luxo é um reflexo da disparidade de riquezas e da desigualdade social, com efeito, se contrapõe aos costumes republicanos ${ }^{18}$.

Essa tese orienta Rousseau a disparar duras críticas a Voltaire ${ }^{19}$, que via o luxo como o reflexo do esplendor dos Estados. Rousseau refuta duramente a perspectiva voltairiana ao sustentar que o luxo cria uma mentalidade fundada na visão de que tudo tem preço e pode ser comprado; inclusive a liberdade e a virtude.

17 Gérard Namer comenta que, segundo a teoria rousseauísta, a degradação dos costumes instala, a imoralidade dos cidadãos, já a virtude moral é uma condição para a atuação política na república. Como a corrupção dos costumes se apoia em acordos beneplácitos que visam unicamente suprir interesses privados, surgem daí inúmeros abusos que corroem toda a ordem republicana.

${ }^{18}$ Em nossa percepção, especialmente, os seguintes: a frugalidade, a moderação, a vida simples e a virtude cívica. Helena Rosenblatt (1997), com quem estamos em conformidade, ressalta que o luxo é incompatível com o republicanismo porque deixa os homens frouxos e efeminados fazendo com que eles se tornem obcecados pelos seus interesses pessoais em contraposição ao bem público. O luxo causa a decadência moral e introduz a corrupção na república. Em certa medida a comentadora endossa o ponto de vista de Judith Shklar (1985), como mostraremos no nosso último tópico. Em nossa percepção, está claro que para Rousseau o luxo se inscreve como um símbolo da corrupção.

${ }^{19} \mathrm{Em}$ seu poema $\boldsymbol{O}$ mundano, Voltaire argumenta que o luxo traz vantagens materiais para os países.

ALVES, Vital Francisco Celestino. A relação entre a desigualdade e a corrupção política na filosofia de Rousseau. Griot : 
Para dar sustentação ao seu ponto de vista, o cidadão de Genebra compara os políticos da antiguidade com os do seu século e declara que, enquanto os antigos políticos discutiam com demasiada frequência a importância dos costumes e das virtudes, os de hoje apenas debatem sobre comércio e dinheiro ${ }^{20}$. E em sua opinião, o mais relevante para um Estado é que ele tenha durabilidade e seja constituído de cidadãos virtuosos, de almas honestas e não de pessoas com preocupações inúteis e destituídas de coragem.

O luxo, explica Rousseau, estimula os artistas a produzirem obras visando tão somente serem elogiados. Para angariar esses elogios, os homens imolam seu gosto aos usurpadores da sua liberdade e desempenharão qualquer papel para adquiri-los. Nessas conjunturas, as obras-primas se evaporam e o gênio se nivelará ao patamar vigente em seu século, dando preferência pela produção de obras triviais de qualidade e relevância dúbias, que perdurarão no máximo até o fim da existência do artista, isto é, não resistirão ao maior teste para uma obra de arte, a sua permanência e importância na passagem do tempo. A rigor, o luxo promove a corrupção do gosto e, acima de tudo, a dos costumes.

Ao constatar a fé cega depositada nas ciências e a maneira como elas atuam na sociedade, simultaneamente ao aprimoramento das artes e a propagação do luxo em seu século, o autor do Contrato, tencionando abonar sua concepção de que o luxo corrompe os costumes, irremediavelmente reporta-se a Roma republicana para dizer que a virtude militar dos romanos começou a ser aniquilada a partir do momento em que eles passaram a cultivar as belas-artes. Na mesma medida, sinaliza que a cultura das ciências também é desfavorável à coragem dos soldados, porém, mais do que isso, ela afeta frontalmente as aptidões morais. Rousseau pressupõe que a raiz do problema está em uma educação equivocada que refina o espírito e corrompe a nossa capacidade de julgar. Uma educação na qual as crianças aprendem sobre vários conteúdos, porém ignoram a sua própria língua e seus deveres, sendo incapazes de distinguir o erro da verdade. Tal educação possibilita às crianças o acesso a múltiplos conteúdos, mas não contribui para formar os bons cidadãos que a ordenação republicana demanda. Em outros termos, uma educação que desconhece o significado de palavras, tais como: "magnanimidade, equidade, temperança, humanidade e coragem; nunca lhes atingirá o ouvido a doce palavra Pátria" (...) (ROUSSEAU, 1964, p. 24) ${ }^{21}$. Enfim, uma educação que molda exageradamente as crianças, mesmo antes de elas aprenderem a ler, com referências negativas ao invés de modelos de defensores da pátria e homens virtuosos que deveriam ser alvo de admiração pública.

Rousseau versa que tal descomedimento educacional tem como gênese a desigualdade. Esta penetra entre os homens à custa do louvor aos talentos e da desvalorização das virtudes, esse é o seu efeito mais drástico. Pois assim a glória é

\footnotetext{
${ }^{20}$ Percebe-se que nesse trecho, Rousseau remete claramente a Montesquieu. Deve-se recordar que o pensador de Bordeaux apresenta sérias restrições ao comércio e ao luxo nas repúblicas. Mais do que uma referência a Montesquieu, no fragmento do Primeiro discurso aludido Rousseau apresenta uma paráfrase do seguinte trecho do Espírito das leis: "Os políticos gregos, que viviam no governo popular, não reconheciam outra força que pudesse sustentá-los além da força da virtude. Os de hoje só nos falam de manufaturas, de comércio, de finanças, de riquezas e mesmo de luxo". (Livro 3, cap. III). ${ }^{21}$ Magnanimité, d'équité, de tempérance, d'humanité, de courage, ils ne sauront ce que c'est; ce doux nom de Patrie. PD, II. OCR3. (Tradução nossa).
}

ALVES, Vital Francisco Celestino. A relação entre a desigualdade e a corrupção política na filosofia de Rousseau. Griot : 
postulada acima da virtude e das boas ações. As condecorações são outorgadas aos discursos sublimes, mas não para as ações louváveis. Como consequência, o restabelecimento das ciências e das artes tornou a sociedade repleta de cientistas e artistas, mas eximiu-se de formar cidadãos. Não temos mais cidadãos ${ }^{22}$, afirma categoricamente o cidadão de Genebra.

\section{Consequências da desigualdade social}

Analisando o problema da desigualdade social na reflexão promovida por Rousseau, pode-se atestar que no Discurso sobre as ciências e as artes a discussão sobre a desigualdade gravita entre os homens mediante a uma valorização excessiva dos talentos comparados às virtudes. Enquanto no Segundo discurso Rousseau mostra o processo da desigualdade elencando como as diferenciações surgem e como os vícios emanam e se alargam na medida em que os homens passam a se aproximar e a conviver entre si e a maneira como a desigualdade atinge seu ápice com o advento da propriedade e a consolidação do pacto dos ricos. Embora o tema da desigualdade permeie as duas obras e haja notáveis distinções em suas respectivas abordagens, estamos plenamente em consonância com Paul Arbousse-Batisde (1997), ou seja, pensamos que o enfrentamento dado por Rousseau ao tema da desigualdade, em ambos escritos, tem como pano de fundo a política.

Pode-se considerar, mediante os textos rousseaunianos dos quais nos valemos, que a desigualdade é um fenômeno perigoso e colabora abertamente para o desabrochar da corrupção política. Provavelmente, essa constatação, faz com que o cidadão de Genebra no Contrato social - obra em que expõe com maturidade o seu pensamento político -, se posicione com veemente objeção à desigualdade social, pois ela contribui para a acumulação dos abastados e conduz ao luxo que:

[...] ou é efeito de riquezas ou as torna necessárias; corrompe ao mesmo tempo o rico e o pobre, um pela posse e outro pela cobiça; entrega a pátria à frouxidão e à vaidade. (ROUSSEAU, 1964, p. 405). ${ }^{23}$

O fragmento destacado enuncia a oposição de Rousseau ao luxo e é possível atestar, em decorrência dele, os motivos pelos quais o luxo deve ser rechaçado, isto é, o luxo, ao ressaltar a desigualdade social, igualmente fomenta a corrupção. Na interpretação de Judith Shklar (1985), ao contrapor-se ao luxo o filósofo genebrino tem em vista o fato de que ele torna os homens brandos e servis e reconhece que o luxo não só contribui para a acentuação da desigualdade e difunde a corrupção

\footnotetext{
${ }^{22}$ Em nota de rodapé das OCR3, concernente a essa passagem, François Bouchardy (1964) resgata a ideia exposta por Rousseau no Contrato social de que o verdadeiro sentido do termo "cidadão" praticamente se perdeu entre os modernos. Para o filósofo genebrino, cidadão não quer dizer apenas uma virtude, mas um direito. Desse modo, o Primeiro Discurso é uma tentativa de reanimar a virtude para posteriormente reivindicá-la como direito. Paul Arbousse-Bastide (1997) defende também em nota, na edição brasileira de Os Pensadores (tradução de Lourdes Santos Machado), que esse trecho enuncia claramente a perspectiva política de Rousseau no Discurso sobre as ciências e as artes.

${ }^{23}$ (...) ou le luxe est l'effet des richesses, ou il les rend nécessaires; il corrompt fois le riche et le pauvre, l'um par la possession l'autre par la convoitise; il vend la patrie à la molesse à la vanité. CS, III, IV. OCR3. (Tradução nossa).
}

ALVES, Vital Francisco Celestino. A relação entre a desigualdade e a corrupção política na filosofia de Rousseau. Griot : 
política, como também suprime a virtude cívica ${ }^{24}$.

Ao constatar que a desigualdade gera o luxo e consequentemente desencadeia a corrupção, convém questionar: qual seria a consequência mais devastadora da desigualdade social ao engendrar o luxo e a corrupção política na República? Avaliase que a disparidade entre ricos e pobres abre a possibilidade também para que um cidadão passe a depender de uma vontade alheia à sua. $\mathrm{O}$ que, por conseguinte, pode induzi-lo a trocar a sua liberdade pela riqueza de outrem; em linhas gerais, caso alguém se encontre em posição de destituição material e vende-se a um homem rico, comprometendo-se a obedecê-lo, ele estará renunciando à sua liberdade e, para Rousseau, renunciar à liberdade é renunciar à qualidade de homem (ROUSSEAU, 1964, p. 356) ${ }^{25}$. Portanto, a consequência mais terrível das diferenças sociais, ao provocar a corrupção, é a dependência pessoal, logo, a dissipação da liberdade ${ }^{26}$. Dissipação que resulta na aniquilação da própria humanidade do homem.

Essa interpretação que apresentamos encontra amparo nas leituras de alguns intérpretes de Rousseau. Por exemplo, segundo Jean-Fabien Spitz (1995), a dependência de uma vontade particular arbitrária suscitada pela desigualdade social destrói a liberdade do homem, pois ele deixa de ser dono de si mesmo. Para Derathé (1950), na filosofia de Rousseau ninguém pode ser livre se estiver submetido à vontade de outro homem, mas isso por si só não basta para ser livre, uma vez que, de acordo com Rousseau, um homem livre não obedece a outra vontade além da sua ${ }^{27}$ (Derathé, 1950, p. 231). Maurizio Viroli (2002) avaliza tais pontos de vista e acrescenta que a desigualdade social, na teoria política de Rousseau, ao incitar o luxo e, inexoravelmente, a corrupção, permite a alguns homens comprar ou vender algo que na república é invendável: a liberdade.

Considerando a interpretação que apresentamos e a ilustração oferecida pelos comentadores aludidos, avaliamos que quando Rousseau proclama no Manuscrito de Genebra a máxima: que nenhum cidadão tenha opulência necessária para comprar outro e que "nenhum seja pobre o bastante para que se veja forçado a vender-se" (ROUSSEAU, 1964, p. 332) ${ }^{28}$, e depois retoma essa ideia, realçando-a na versão definitiva do Contrato social, faz com que depreendamos nitidamente porque a igualdade, conforme ele, ambicionada no seu arranjo político, apresenta-se como valor fundamental para a manutenção da liberdade. É justamente prevendo os riscos iminentes que a desigualdade social pode fomentar na república, acima de tudo o luxo e a corrupção - desdobramentos que comprometem a liberdade - que Rousseau busca demonstrar que, juntamente com a igualdade de participação nas assembleias ${ }^{29}$, e perante a lei, a ordem republicana requer moderação. Tal fato, nos

\footnotetext{
${ }^{24}$ Fundamento primordial para a conservação da república e que consiste no amor à pátria. A virtude cívica é um sentimento que mobiliza os cidadãos a defenderem o bem público e a liberdade.

${ }^{25}$ Renoncer à as liberte c'est renoncer à as qualité d'homme. CS, I, IV. OCR3. (Tradução nossa).

${ }^{26}$ Visto que, como se sabe, ser livre em Rousseau significa obedecer à própria vontade.

27 Um homme libre n'obéit à d'autre volonté que la sienne. Jean-Jacques Rousseau et la Science politique de sons temps. (Tradução nossa).

${ }^{28}$ Que nul Citoyen ne soit assés opulent pour em pouvoir acheter un autre, et nul assés pauvre pour être contraint de se vendre. MG, II, VI. OCR3. (Tradução nossa).

29 Há no pensamento rousseauniano a defesa de que os cidadãos participem ativamente das assembleias públicas que devem ser fixas e periódicas. Nessas assembleias eles buscarão identificar a vontade geral e daí elaborarão leis que enunciem o bem-comum.
}

ALVES, Vital Francisco Celestino. A relação entre a desigualdade e a corrupção política na filosofia de Rousseau. Griot : 
termos do autor, supõe "nos grandes moderação de bens e de crédito e, nos pequenos moderação da avareza e da cupidez" (ROUSSEAU, 1964, p. 392) ${ }^{30}$, isto é, o mais relevante para ele é que não existam desigualdades sociais profundas a ponto de permitirem o cultivo do luxo, o qual produz a corrupção e resulta na perda da liberdade.

Malgrado, a república apresentada por Rousseau tem na corrupção uma ameaça constante, cuja origem tem como uma das principais causas a desigualdade social. Esse nosso ponto de vista, encontra suporte especificamente nas análises de Spitz (1995). Na visão desse comentador a desigualdade de condições materiais permite aos ricos submeter os pobres a uma condição de dependência pessoal. Na ocasião em que se perde a independência e os alicerces materiais se concentram nas mãos de poucos, as melhores leis se tornam débeis e inoperantes frente à cobiça por dominação. O dinheiro possibilitará aos ricos comprar os votos e impor leis que favoreçam apenas a eles mesmos, para isso não terão escrúpulos de corromper importantes funcionários da ordenação republicana. Na Economia política, Rousseau deixa claro que quando há ricos e pobres não pode existir a república, pois a disparidade entre as classes sociais obstrui a possibilidade de haver o interesse comum e obviamente impossibilita um reconhecimento recíproco da legitimidade entre os que possuem tudo e os materialmente desamparados.

A desigualdade de fortunas tem demasiados efeitos, entre eles a supressão do amor ao bem público e o aviltamento do patriotismo. Ora, questiona ainda Spitz: quando as leis ocupam-se mais dos ricos do que dos pobres, quando elas são constituídas para propagar a desigualdade, como a soma dos cidadãos poderá se considerar parte da ordem política? Como poderão conservar-se diligentes na conservação das instituições e ter tenacidade para defendê-las? Tendo em vista, a problematização inserida pelo intérprete mencionado, é razoável concluir, em nossa interpretação, que a desigualdade social afugenta os cidadãos do bem público e gera uma prevalência dos interesses particulares. Ao operar essa divisão surge uma espécie de privatização dos interesses individuais e a liberdade deixa de ser um valor aprazível. Esse arranjo, portanto, não condiz com uma perspectiva política republicana balizada no bem público e na liberdade.

\footnotetext{
30 Ce qui suppose du côte des grands modération de biens et de crédit, et du côté des petits, modération d'avarice et de convoitise. CS, II, XI. OCR3. (Tradução nossa).
} 


\section{Referencias bibliográficas}

BURGIO, Alberto. Eguaglianza interesse unanimità - La politica di Rousseau. Napoli: Bibliopolis, 1989.

DENT, N.J.H. Dicionário Rousseau. Rio de Janeiro: Zahar, 1996.

DERATHÉ, Robert. Jean-Jacques Rousseau et la Science politique de son temps. Paris: VRIN, 1950.

LAUNAY, M. Jean-Jacques Rousseau, écrivan politique. Grenoble: CEL/ACER, 1971.

MAQUIAVEL, N. Discurso sobre a primeira década de Tito Lívio. São Paulo: Martins Fontes, 2007.

MONTESQUIEU. O espírito das leis. São Paulo: Nova Cultural, 1997 (Os

Pensadores).

NAMER, Gérard. Le système social de Rousseau - de l'inéqualité économique à l'inégalité politique. Paris: L'Harmattan, 1999.

ROSENBLATT, Helena. Rousseau and Genebra - From the first discourse to the social contract, 1749-1762. New York : Cambridge University Press, 1997.

ROUSSEAU, J.-J. Oeuvres complètes. Paris: Gallimard, Volumes I, II, III et IV 1959, 1961, 1964, 1969. (Bibliothèque de La Pléiade)

Do Contrato Social. Tradução de Lourdes Santos Machado;

Introdução e notas de Paul Arbousse-Bastide e Lourival Gomes Machado São Paulo: Nova Cultural, 1997. (Os Pensadores).

Rousseau e as relações internacionais. São Paulo: Imprensa Oficial do

Estado e Editora Unb, 2003.

SHKLAR, Judith N. Jean-Jacques Rousseau and Equality. Journal of the American Academy of Arts and Sciences, from the issue entitled "Rousseau for our time", 107, n. 3,I 1978. p. 13-25.

- Men and Citizens - $A$ study of Rousseau's social theory. Cambridge studies in the history and theory of politics. London: The University of Chicago and London, 1985.

SPITZ, Jean-Fabien. La liberte politique - Essai de généalogie conceptuelle. Paris: Presses Universitaires de France, 1995.

VIROLI, Maurizio. Jean-Jacques Rousseau and the 'well-ordered society'. Cambridge: Cambridge University Press. UK, 2002.

VOLTAIRE. “Le Mondain". In: L’Apologie du luxe au XVIII siècle. Étude critique sur Le Modain e ses sources. Paris: H. Didier Libraire-éditeur, 1909b.

Autor(a) para correspondência: Vital Francisco Celestino Alves, Universidade de Brasilia, Instituto de Ciências Humanas, Campus Universitário Darcy Ribeiro, CEP 70910-900, Brasília - DF, Brasil. vitalalves1@gmail.com

ALVES, Vital Francisco Celestino. A relação entre a desigualdade e a corrupção política na filosofia de Rousseau. Griot : 